\title{
Article \\ The Influence of Dense Planting System on the Technical Efficiency of Saffron Production and Land Use Sustainability: Empirical Evidence from Gonabad County, Iran
}

\author{
Mohammadreza Ramezani ${ }^{1}$ (D), Arash Dourandish ${ }^{2}$, Tinoush Jamali Jaghdani ${ }^{3, * \mathbb{D}}$ and Milad Aminizadeh ${ }^{1}$ \\ 1 Department of Agricultural Economics, Ferdowsi University of Mashhad (FUM), \\ Mashhad 9177948978, Iran; mr.ramezani@mail.um.ac.ir (M.R.); milad.aminizadeh@mail.um.ac.ir (M.A.) \\ 2 Department of Agricultural Economics, College of Agriculture \& Natural Resources, University of \\ Tehran (UT), Karaj 7787131587, Iran; dourandish@ut.ac.ir \\ 3 Department of Agricultural Markets, The Leibniz Institute of Agricultural Development in Transition \\ Economies (IAMO), 06120 Halle, Germany \\ * Correspondence: jaghdani@iamo.de; Tel.: +49-345-2928-218
}

check for updates

Citation: Ramezani, M.; Dourandish, A.; Jamali Jaghdani, T.; Aminizadeh, M. The Influence of Dense Planting System on the Technical Efficiency of Saffron Production and Land Use Sustainability: Empirical Evidence from Gonabad County, Iran. Agriculture 2022, 12, 92. https://doi.org/10.3390/ agriculture12010092

Academic Editors: Vítor João Pereira Domingues Martinho, Paulo

Reis Mourão and

Nikolaos Georgantzis

Received: 3 December 2021

Accepted: 5 January 2022

Published: 11 January 2022

Publisher's Note: MDPI stays neutral with regard to jurisdictional claims in published maps and institutional affiliations.

Copyright: (C) 2022 by the authors. Licensee MDPI, Basel, Switzerland. This article is an open access article distributed under the terms and conditions of the Creative Commons Attribution (CC BY) license (https:// creativecommons.org/licenses/by/ $4.0 /)$.

\begin{abstract}
The cultivation of saffron, which is one of the most expensive agricultural products in the world, is the main source of livelihood and economic wellbeing for the rural communities of Gonabad county in the eastern part of Iran. Nevertheless, farm monitoring in the region has shown that many saffron growers apply a high-density planting system for more profit. This practice results in the loss of land productivity after a six-year production cycle. As a consequence, farmers abandon the cultivated lands and move to plant saffron in available virgin lands. The purpose of this study is to analyse the technical efficiency of saffron farms and its determinants with an emphasis on the role of planting density. A survey was conducted in 2019, and a cross-sectional random sampling technique was used to select 110 saffron growers. We first assessed the technical efficiency of farms using a data envelopment analysis (DEA) model with input orientation. In the next step, efficiency scores were regressed on explanatory variables using OLS and bootstrapped truncated regression to identify efficiency related factors. We find that planting density negatively influenced technical efficiency, suggesting that it is necessary for saffron growers to be educated on the negative impacts of the dense planting system.
\end{abstract}

Keywords: efficiency; data envelopment analysis (DEA); saffron; corm planting density; Iran; Gonabad county

\section{Introduction}

Collected from the saffron plant (Crocus sativus L.), saffron is by far one of the most expensive spices and agricultural products [1]. It has gradually become more popular and is used for a number of diverse applications in the clothing (dyeing), cosmetics, medicine, and food industries [2]. Saffron is currently cultivated in various climatic conditions, such as in arid countries in southern Europe, North Africa, Middle East, and Central Asia, which are areas with low precipitation, hot summers, and cold winters [3]. Iran, India, Greece, Afghanistan, Morocco, Spain, Italy, China, and Azerbaijan are the major saffron producing countries [4]. Moreover, the acreage of cultivated saffron is increasing in some countries, such as Turkey, Pakistan, France, and the United States [5]. It must be added that the World Bank has recognised the saffron plantation as a source of income for farmers in Afghanistan that could encourage them to distance themselves from poppy production [6]. Afghanistan is the major producer of poppies and, as a result, drugs in the world, which causes threats to international security [7]. Therefore, the plantation of saffron as an alternative source of income has been encouraged in Afghanistan in recent years to replace poppy plantations. Nevertheless, with a total export value for saffron amounting to USD 351 million, Iran 
accounted for $71.3 \%$ of the world's total saffron export value in 2018 [8]. Saffron production in Iran is an old tradition [9], and it is a strategic product in the two neighbouring provinces of southern Khorasan and Khorasan Razavi, which are both located in northeast Iran [4,10]. Saffron's unique growing characteristics, such as its low water requirements, its adaptation to Iran's climate, and that it does not require heavy or complex machinery to grow, has made Iran the main saffron producer worldwide.

Despite the undeniable importance of saffron in Iran's agricultural sector, its average yield per hectare has reduced drastically in recent years, from $6.15 \mathrm{~kg} / \mathrm{ha}$ per year in 1971 to $3.42 \mathrm{~kg} /$ ha per year in 2017 [11]. Part of this decline is due to exogenous factors, such as droughts and global warming [12], while endogenous factors, such as mismanagement and the inappropriate use of production inputs, has also had a deteriorating impact on the yield of saffron farms and farmers' incomes in previous years [13]. Based on these numbers, it can be concluded that Iranian saffron growers are not obtaining the maximum output from the resources devoted to saffron production, showing that there are resource use inefficiencies in Iran's saffron cultivation. Thus, it is necessary and beneficial to improve the efficiency of saffron cultivation through the application of the optimum level of inputs. However, increasing efficiency and productivity should also be accompanied by the sustainable use of natural resources and environmental protection [14]. It is evident that the farming systems that apply inputs intensively and over-exploit natural resources are unsustainable and responsible for numerous challenges, such as water shortages, soil degradation, and groundwater contamination [14,15]. Among agricultural inputs, land is one of the most essential ones that must be used in a sustainable manner to achieve both productivity and sustainability goals [16]. Land degradation is internationally defined as one of the indicators of non-sustainability in agriculture [17,18].

Saffron is a perennial plant that is propagated by corm. After flowering, each corm produces two or three corms called daughter corms. Daughter corms develop to replace the parent, and this process continues for several years, which can lead to overcrowded saffron farms with insufficient space left for corms to develop and be harvested at optimum yields. In saffron cultivation, high corm planting density is a common practice, which could be the reason for the reduction in the yields of saffron farms. Although high corm planting density can result in a better performance of saffron in the early years of cultivation and an earlier start for harvesting, it could have a damaging impact on the performance of the crop in later years because of overcrowding. As a result, the farm might need to be dug up to move the corms to a new plot [19-22]. The continuous planting of saffron in the same plot causes a significant reduction in saffron growth and flowering, probably due to the accumulation of ions, toxins, salts, and allelopathic substances in the root zone [23]. Some local farmers believe that such plots are out of operation for saffron forever. In some cases where saffron was planted continuously, a severe decrease in production was observed. This has been observed in the saffron production of other countries, such as Morocco [19] and Italy [24], as well. Therefore, it should be taken into consideration that dense plantation systems may not only be unable to enhance saffron production efficiency, but may also result in resource use inefficiencies.

Recent studies on crop production efficiency have focused on similar issues. For instance, Zulfiqar et al. [25] measured the resource use efficiency of cotton farmers using a DEA model. The mean technical efficiency was 0.79 , and they found that nearly $97 \%$ of farmers could reduce their use of seeds while still being able to achieve the same output levels. They also carried out a truncated regression model to identify efficiency-related factors. Education, farming experience, drainage status, area under cotton, and the number of household members involved in farming had a significant effect on technical efficiency. Using the framework of DEA, Mukhtar et al. [26] analysed the technical efficiency of smallholder pearl millet farmers in Nigeria and came up with similar findings, showing that farmers could reduce seeding materials while sustaining the same level of yields. On the contrary, in a study on the technical efficiency of poultry-vegetable integration in Tanzania, Habiyaremye et al. [27] showed that a 1\% increase in the cost of vegetable 
seeds increased the quantity of vegetable produced by $0.15 \%$. Their stochastic frontier analysis (SFA) results revealed that the mean technical efficiency of this production system is 0.44 , which is significantly below most studies on vegetables. Age and gender were the most important determinants of technical efficiency. There are also several studies in the literature that have assessed the factors affecting the efficiency of crop production without mentioning the effects of seeds/seedlings on production and efficiency. For example, Mengui et al. [28] employed a two-step DEA-Tobit approach for analysing the technical efficiency of Irish potato farms in the Santa subdivision of Cameroon. They pointed out that potato producers could reduce their inputs by $33.7 \%$ and still produce the same level of potato output. Gender, age of household head, farming experience, farm size, use of manure, years of schooling, extension services, and receiving credit were found to have significant impacts on the efficiency scores. Finally, and more recently, Attipoe et al. [29] applied an SFA model to investigate the technical efficiency of cocoa production and the factors influencing it in Ghana. The overall technical efficiencies of all sampled farms were less than 1 , with a mean of 0.81 . They also concluded that credit-takers were more likely to exhibit higher levels of efficiency. Regarding the importance of saffron in Iran's agricultural sector, a few studies (written in the Persian language) have also assessed the efficiency of saffron production and its determinants; however, none of them to-date have addressed the fact that saffron yields are highly dependent on primary corm planting density and the cultivation age of farms.

With this background, the main issue of our interest is the influence of the dense planting system on both the efficiency and land use sustainability of saffron production. In this study, we focus on this issue and investigate the determinants of technical efficiency in saffron production with an emphasis on the role of planting density. To the best of our knowledge, this paper is the first attempt to explicitly test the impact of dense planting on the efficiency of saffron farms. The rest of this paper is structured as follows: The next section describes the study area, our data gathering process and methodology, while section three provides the empirical results, which is followed by the discussion in section four. Finally, the conclusion and policy implications are provided in section five.

\section{Materials and Methods}

\subsection{Study Area}

Located in the southern part of the Khorasan Razavi province of Iran and near to the Afghanistan border, Gonabad county was selected as the study area (see Figure 1). The region is historically well known for farming activities, especially saffron cultivation. Apart from saffron, grapes, pistachios, cumin, wheat, barely, pomegranate, and almonds are also produced in this area. In spite of suffering from and being affected by droughts for several years, saffron farming is still one of the most important activities in this region due to the crop's high drought resistance. From the 14,300 hectares of available arable land in Gonabad county, almost 3600 hectares are allocated to saffron cultivation, with a total annual production of 10.8 tonnes, accounting for $40 \%$ of all income from agricultural products in the county [30]. Farm monitoring shows that saffron growers in Gonabad have a tendency to plant saffron in high densities. Appropriate corm planting density for the saffron fields of Gonabad was estimated to be at a level of 3.2 tonnes of corms/ha among experienced farmers. However, our observations imply that about $40 \%$ of farmers practice higher corm planting densities of up to 7 tonnes/ha. 


\section{Study Area in Iran}

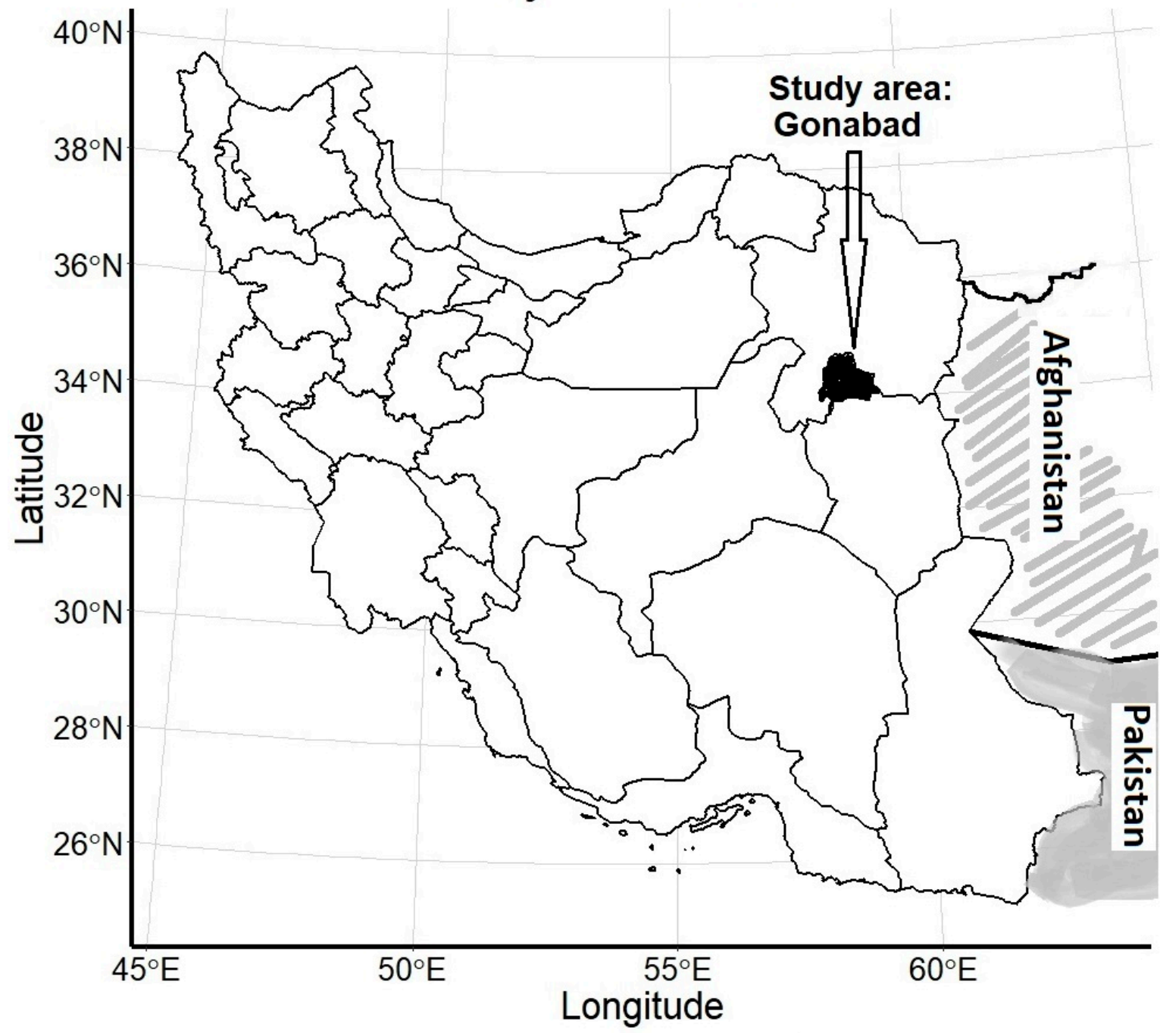

Figure 1. The map of the study area (own elaboration with the help of the ggplot2 package in R [31]).

\subsection{Data Collection and Questionnaire}

A field study and survey were conducted in 2019 to acquire the necessary data. The survey consisted of three different categories of questions. In the first category, we obtained the data needed regarding the inputs and outputs of the farms' saffron production for the year of data collection. In the second category, we collected the socio-economic characteristics of the respondents. In the third category of questions, saffron growers were asked to provide input-output data over a six-year time period based on local available knowledge. According to experienced saffron farmers, the flowering life of saffron plants varies between 10 to 15 years if corm planting density is kept at around 3.2 tonnes/ha. With higher corm planting density, the flowering life may drop to six years. This local knowledge has also been confirmed by Koocheki and Seyyed [12], who observed that saffron fields in Iran can survive for at least six years. In our sample, farmers had different starting points for corm planting; therefore, some farms were less than six years old at the point of data collection. In those cases, input-output production data were not available for some years. Thus, we had an unbalanced panel of data over a six-year production cycle that we used to estimate the technical efficiency of saffron farms from both a shortand long-term perspective. In this way, short-term and long-term refer to one-year and six-year growing cycles, respectively. The validity of this questionnaire was confirmed by 
eight experts, of whom three were practitioners and the rest were researchers in the field of saffron cultivation.

To obtain the sample size, a pilot survey was conducted with 30 farmers. Afterwards, the sample size was determined according to the following formula [32]:

$$
n=\frac{t^{2} \cdot S^{2}}{d^{2}}
$$

where $t$ is the critical value for the desired level of statistical confidence, $d$ refers to the acceptable error, and $S$ is the standard deviation of the studied quantitative variable (corm planting density). Finally, the sample size was estimated to be 114. Applying a systematic random sampling technique, the farmers were selected, and the final questionnaire was distributed among them. Four questionnaires were excluded from the analysis due to large amounts of missing information; thus, a total number of 110 questionnaires were considered for the statistical analysis.

\subsection{Analytical Framework: OLS and Bootstrapped Truncated Regression as the Second Stage of DEA Efficiency Analysis}

A two-step model was considered here. In the first step, a DEA model was used to measure the technical efficiency of the saffron farms. In the second step, the relationship between the technical efficiency measure and other relevant variables that were predicted to affect the efficiency of farms was assessed using ordinary least squares (OLS) and bootstrapped truncated regression (BTR). These utilised models are explained below.

\subsubsection{Data Envelopment Analysis}

According to Farrell [33], a decision making unit (DMU) is considered to be technically efficient if it utilises the minimum levels of inputs for producing a given quantity of outputs under certain technology. Farrell suggested a frontier function to measure the technical efficiency of a firm. Since then, production frontiers have been estimated using different methods. The two most popular and commonly used techniques are data envelopment analysis (DEA), which applies mathematical programming, and stochastic frontier analysis (SFA), which employs econometric techniques.

The DEA that we employed in this study was first introduced by Farrell and further developed by Charnes et al. [34]. It is a nonparametric approach based on a sequence of linear programs. When compared to the SFA approach, the DEA has some advantages. First, the DEA does not need to meet assumptions concerning the functional form for the frontier technology or the distribution of the inefficiency term, whereas the SFA approach heavily depends on the choice of the functional form and the distribution of a sample, and errors are presupposed [35]. Second, the DEA suggests how to reallocate the input/outputs in order to achieve technical efficiency [36]. Third, along with producing efficiency scores, the DEA generates information about the benchmark firms for each individual firm in the sample, which can provide guidelines for management [37]. DEA models have been considerably extended to measure the technical efficiency of agricultural products.

DEA models can be input- or output-oriented. An input-oriented DEA seeks to minimise inputs to achieve a desired level of outputs. An output-oriented DEA, on the other hand, searches for the possible maximum outputs while the levels of the inputs are maintained constant. As the agriculture sector relies on limited inputs, an input-orientated model is more appropriate [38]. Hence, we measure efficiency under the presumption that a DMU needs to produce a fixed level of outputs but aims to reduce the consumption of inputs. Because each DMU uses a different quantity of inputs to produce different levels of outputs, the method compares each DMU with the efficient production frontier, which is identified through the input-output data of all DMUs. The DEA model can operate under the assumption of either constant or variable returns to scale. Efficiency in the constant return to scale (CRS) model refers to the overall technical efficiency, whereas in the variable 
return to scale (VRS) model, efficiency refers to pure technical efficiency, which isolates the scale effect from the efficiency scores.

The mathematical model of input-oriented DEA can be defined as follows (see Coelli et al. [39]): Let us assume that for each of the $i$-th DMUs, there are $N$ inputs (represented by $x_{i}$ ) and $M$ outputs (represented by $q_{i}$ ). The $N \times 1$ input matrix, $X$, and $M \times 1$ output matrix, $Q$, represent the data for all DMUs. The primal form of the input-oriented VRS linear programming problem model is given as follows (the notation "st" stands for "subject to"'):

$$
\begin{array}{cc}
\min _{\theta, \lambda} \theta, & \\
\text { st } & -\boldsymbol{q}_{i}+Q \lambda \geq 0, \\
\theta x_{\boldsymbol{i}}-X \lambda \geq 0, \\
\boldsymbol{I} 1^{\prime} \lambda=1, \\
\lambda \geq 0,
\end{array}
$$

where $I 1$ is an $I \times 1$ vector of ones, $\lambda$ is an $I \times 1$ vector of constraints, and $\theta$ is a scalar. The estimated value of $\theta$ is the technical efficiency (TE) score for the $i$-th DMU. The constraint $\theta \leq 1$ should be held. The value of one for the parameter indicates a point on the frontier where maximum technical efficiency is achieved. The above linear programming problem must be solved I times, once for each DMU in the sample. Using TE scores from the VRS and $C R S$, the values of the scale efficiency $(S E)$ for each DMU is computed as follows:

$$
S E_{i}=\frac{T E_{i, C R S}}{T E_{i, V R S}}
$$

If the scale efficiency is equal to one, the firm operates at an optimal scale. Nevertheless, if the value of the scale efficiency is less than one, the firm operates with a decreasing or increasing return to scale.

In this study, we follow a sequential approach, proposed by Pastor et al. [40], to select variables for DEA analysis. To this end, we firstly detected all the inputs used by saffron farmers in the region and, then, a backward elimination procedure was implemented to remove redundant variables. To be precise, the efficiency contribution of a given variable (called the candidate) is tested from a statistical perspective. Two DEA models are considered, one with the candidate variable and the other one without it, and a binomial test is performed to evaluate the significance of the efficiency contribution of the candidate. We finally selected one output and six inputs to measure the technical efficiency of saffron production. The output was harvested saffron flowers $(\mathrm{kg})$ and the inputs were land (ha), saffron corm (tonne), labour used from land preparation to harvest (person/year), water (cubic metres), chemical fertiliser ( $\mathrm{kg})$, and cow manure (tonne).

\subsubsection{Second Stage of DEA Efficiency Analysis}

The measurement of TE does not have many policy implications by itself, and it does not provide any explanations about the reasons for inefficiencies. Factors that affect TE are the major issues of interest. Many researchers have implemented a Tobit regression model for the second-stage analysis of DEA efficiencies to determine the influential factors on $\mathrm{TE}$, as the efficiency scores fall between zero and one [28,41-44]. However, some studies, such as Hoff [45] and McDonald [46], argue that the Tobit model is not always the most appropriate approach for modelling the factors affecting the DEA scores. In his paper, McDonald [45] advocates for the use of OLS as the second stage of DEA analysis, stating that "a careful OLS analysis will often be sufficient". In the same vein, Banker and Natarajan [46] encourage the use of OLS in the second stage, since it provides consistent estimates. Simar and Wilson [47] also provide evidence that using the Tobit model in the second stage gives such a poor estimation that none of the estimated values are even near to the true values. They claimed that the situation is much better for the truncated regression and, therefore, proposed the use of a bootstrapped truncated regression (BTR), which could provide more accurate and consistent estimations. In order to avoid any bias in the estimates and test 
the robustness of the OLS results, we use the BTR (algorithm II) proposed by Simar and Wilson [47] as an alternative model, with which we obtained almost the same results, with minor differences that were permissible. In order to present the mathematical framework of the bootstrapped-based approach applied in our study, we adapt the following procedure based on Simar and Wilson [47] and López-Penabad et al. [48]. The model can be expressed as:

$$
\hat{\delta}_{i}=z_{i} \beta+\varepsilon_{i}
$$

where $\hat{\delta}_{i}$ represents the TE for the $i$-th DMU, $z_{i}$ is a vector of explanatory variables expected to affect TE scores, $\beta$ is the vector of parameters to be estimated in the second stage, and $\varepsilon_{i}$ is the normally distributed error term, defined as $N\left(0, \sigma_{\varepsilon}^{2}\right)$, with left truncation at $\left(1-z_{i} \hat{\boldsymbol{\beta}}\right)$. The following procedure can be used to obtain bootstrapped truncated regression (BTR) results:

1. Estimate the efficiency scores for all DMUs and use them for further analysis.

2. Use the method of maximum likelihood (ML) to obtain an estimate $\hat{\boldsymbol{\beta}}$ of $\boldsymbol{\beta}$, as well as $\hat{\sigma}_{\varepsilon}$ of $\sigma_{\varepsilon}$, in the truncated regression of $\hat{\delta}$ on $z_{i}$.

3. For each $i=1, \ldots, n$, loop over the next four steps $L_{1}$ times to obtain $n$ sets of bootstrapped estimates $b_{i}=\left\{\hat{\delta}_{i}^{*}\right\}_{l=1}^{L_{1}}$ :

i. Draw $\varepsilon i$ from the normally distributed error term with left truncation at $\left(1-z_{i} \hat{\boldsymbol{\beta}}\right)$,

ii. Again for each $i=1, \ldots, n$, estimate $\hat{\delta}_{i}=z_{i} \hat{\beta}+\varepsilon_{i}$,

iii. $\quad$ Produce a pseudo-dataset $\left(x_{i}^{*}, y_{i}^{*}\right)$, where $x_{i}^{*}=x_{i}$ and $y_{i}^{*}=y_{i}\left(\frac{\hat{\delta}_{i}}{\delta_{i}^{*}}\right)$,

iv. Use the pseudo-dataset $\left(x_{i}^{*}, y_{i}^{*}\right)$ to estimate the pseudo-efficiency score DEA $\left(\hat{\delta}_{i}^{*}\right)$.

4. For each $i=1, \ldots, n$, calculate the bias-corrected efficiency estimator $\hat{\hat{\delta}}$ as:

$$
\hat{\hat{\delta}}_{i}=\hat{\delta}_{i}-b i \hat{a} s_{i}
$$

where biâs is the bootstrapped estimator of bias, calculated as:

$$
\operatorname{biâs}_{i}=\left(\frac{1}{L_{1}} \sum_{l=1}^{L_{1}} \hat{\delta}_{i l}^{*}\right)-\hat{\delta}_{i}
$$

5. Regress $\hat{\hat{\delta}}_{i}$ on $z_{i}$ using a truncated maximum likelihood estimation to obtain $\hat{\hat{\beta}}$ of $\beta$, and $\hat{\hat{\sigma}}_{\varepsilon}$ of $\sigma_{\varepsilon}$.

6. Loop over the next three steps $L_{2}$ times to obtain a set of bootstrapped estimates $\zeta=\left\{\left(\hat{\boldsymbol{\beta}}^{*}, \hat{\sigma}_{\varepsilon}^{*}\right)_{l}\right\}_{l=1}^{L_{2}}:$

i. $\quad$ For each $i=1, \ldots, n$, draw $\varepsilon_{i}$ from the normally distributed error term with left truncation at $\left(1-z_{i} \hat{\hat{\beta}}\right)$,

ii. $\quad$ Again for each $i=1, \ldots, n$, estimate $\delta_{i}^{* *}=z_{i} \hat{\hat{\beta}}+\varepsilon_{i}$,

iii. $\quad$ Regress $\delta_{i}^{* *}$ on $z_{i}$ using a truncated maximum likelihood estimation to obtain $\hat{\hat{\beta}}^{*}$ of $\beta$, and $\hat{\sigma}_{\mathcal{\varepsilon}}^{*}$ of $\sigma_{\varepsilon}$.

7. Use the values in $\zeta$ to calculate the confidence interval and standard errors for $\hat{\hat{\beta}}$ and $\hat{\sigma}_{\varepsilon}$ from the bootstrap distribution of $\hat{\hat{\beta}}^{*}$ and $\hat{\sigma}_{\varepsilon}^{*}$.

Following Hall [49], the number of bootstrap replications was 1000 in order to construct correct confidence intervals.

The models are estimated with cross-sectional and panel data separately. Firstly, by considering the available studies on TE and the empirical findings for saffron to-date, we 
selected the following exogenous variables to test their effects on the farms' efficiency with cross-sectional data. The empirical OLS and BTR for this study were specified as follows:

$$
\begin{aligned}
\text { TE }_{i}=\beta_{0}+\beta_{1} \text { Age }_{i} & +\beta_{2} \text { Education }_{i}+\beta_{3} \text { Training }_{i}+\beta_{4} \text { Income }_{i} \\
& +\beta_{5} \text { Insurance }_{i}+\beta_{6} \text { HouseholdSize }_{i}+\beta_{7} \text { Corm }_{i} \\
& +\beta_{8} \text { FarmAge }_{i}+\beta_{9} \text { FarmSize }_{i}+\epsilon_{i}
\end{aligned}
$$

where $T E_{i}$ represents the technical efficiency, the $i$ subscript indicates the $i$-th saffron grower in the sample, Age represents a farmer's age (years), Education refers to the level of education (years of schooling), Training represents training courses (a dummy variable, with the value 1 if a farmer attended training sessions and 0 otherwise), Income represents a farmer's income per month (million Iranian Rials (IRR)), Insurance represents the crop insurance (a dummy variable with a value of 1 if a farmer used crop insurance and 0 otherwise), HouseholdSize represents the size of the household (persons), FarmAge refers to the age of the saffron farm (years), Corm stands for corm planting density (tonnes/ha), FarmSize is the size of the farm (ha), and $E$ is error term. The data in Equation (7) belong to the year that the survey is conducted. It is worth noting that since the BTR is a linear model, the marginal effects will be identical to the coefficients, as long as higher-order polynomial terms or interactions are not included in the equation. In the case of our study, in which these terms are not considered, there is no need to calculate marginal effects separately.

Secondly, as discussed in Section 2.2, the main objective of this study is to test the effects of planting density on the technical efficiency of saffron production for both the year of data collection and over a six-year production cycle. As explained before, inputoutput data were not available for some farms for some years. Therefore, efficiency scores are estimated only for farms and years for which data were available to us. In this way, we obtained an unbalanced panel dataset of technical efficiency scores. Afterwards, the efficiency scores were regressed on the corm planting density through both fixed effect and random effect OLS and BTR. The research panel model can be expressed as:

$$
T E_{i t}=\alpha_{0}+\alpha_{1} \ln (\text { Corm })+u_{i}+\eta_{t}+\varepsilon_{i t}
$$

where $i$ represents farmer, $t$ refers to year, TE stands for technical efficiency, $\ln ($ Corm $)$ denotes the natural logarithm of corm planting density (tonnes/ha), $u_{i}$ represents the unobserved individual specific effect, $\eta_{t}$ denotes the unobserved time specific effect, and $\varepsilon_{i t}$ is the error term. The linear logarithmic equation was used based on the Box-Cox test results.

\section{Results}

\subsection{Summary Statistics of the Sample Farms}

Tables 1 and 2 give the summary statistics for the variables used in our study. As mentioned, input-output data have also been collected over a six-year production cycle. However, due to space limits, summary statistics of inputs are provided only for the year of data collection (a summary of the six-year input data can be provided upon request). Furthermore, summary statistics of the output in each year of the six-year cycle are presented in Table 2. 
Table 1. Summary statistics for the variables obtained from the survey in the year of data collection (2019).

\begin{tabular}{|c|c|c|c|c|c|}
\hline & & Mean & SD & Min. & Max. \\
\hline Output per hectare & Harvested saffron flowers (kg/ha) & 426.75 & 345.96 & 20 & 2000 \\
\hline \multirow{6}{*}{ Production input } & Land (ha) & 0.56 & 0.40 & 0.1 & 2 \\
\hline & Saffron corm (tonnes/ha) & 3.17 & 1.28 & 1 & 6 \\
\hline & Labour (person/year/ha) & 54.92 & 30.55 & 10 & 207.15 \\
\hline & Water (cubic metres/ha) & 6480 & 1527.79 & 4050 & 12,150 \\
\hline & Chemical fertiliser $(\mathrm{kg} / \mathrm{ha})$ & 182.79 & 117.73 & 28 & 500 \\
\hline & Cattle manure (tonnes /ha) & 38.20 & 30.11 & 5 & 105 \\
\hline \multirow{9}{*}{$\begin{array}{l}\text { Farm and farmer } \\
\text { characteristics }\end{array}$} & Farmer's age (years) & 49.93 & 13.92 & 24 & 79 \\
\hline & Education (years) & 7.13 & 4.06 & 0 & 16 \\
\hline & Income (IRR million *) & 21.11 & 9.18 & 5.4 & 46.80 \\
\hline & $\begin{array}{l}\text { Household size } \\
\text { (number of persons) }\end{array}$ & 4.67 & 1.91 & 1 & 8 \\
\hline & Planting density (tonnes/ha) & 3.17 & 1.28 & 1 & 6 \\
\hline & Farm size (ha) & 0.56 & 0.40 & 0.1 & 2 \\
\hline & Age of the farm (years) & 5.45 & 3.15 & 1 & 13 \\
\hline & Insurance (dummy) & 0.24 & 0.43 & 0 & 1 \\
\hline & Training course (dummy) & 0.28 & 0.45 & 0 & 1 \\
\hline
\end{tabular}

* 1 USD was equal to IRR 125,000 (Iranian Rials) in 2019.

Table 2. Summary statistics of the amount of harvested saffron flowers $(\mathrm{kg} / \mathrm{ha})$ in the first six years.

\begin{tabular}{lcccc}
\hline & Mean & SD & Min. & Max. \\
\hline 1st year (110 farms) & 131.80 & 104.95 & 10 & 500 \\
2nd year (90 farms) & 302.36 & 187.76 & 20 & 1000 \\
3rd year (81 farms) & 478.11 & 263.50 & 50 & 1428.57 \\
4th year (77 farms) & 580.22 & 303.09 & 150 & 2000 \\
5th year (68 farms) & 635.52 & 322.84 & 150 & 2000 \\
6th year (57 farms) & 670.33 & 361.23 & 100 & 2000 \\
\hline
\end{tabular}

Numbers in parenthesis show the number of farms for which data were available.

The farm size of the saffron farms in the sample ranges from 0.1 ha to 2 ha, with a mean size of 0.56 ha, indicating the dominance of traditional, small-scale farming systems in the region. The amount of saffron corms used in saffron production ranges from 1 tonne/ha to 6 tonnes/ha, with a mean of 3.17 tonnes/ha. As mentioned before, the optimum corm planting density for the saffron fields of the study area has been estimated to be 3.2 tonnes of corms/ha, while some saffron growers preferred to cultivate saffron at higher densities. The average labour use is 54.92 persons / ha, which reveals that saffron is one of the most labourintensive crops. Labour shortages and high expenses for hand weeding and harvesting the flowers are other notable saffron production challenges in the region. The average water consumption is $6480 \mathrm{~m}^{3} /$ ha. Furrow irrigation is a common irrigation practice among farmers and advanced irrigation methods are not commonly used, probably due to higher costs. Water is supplied through two Qanats (a "Qanat" is a gently sloping subterranean aqueduct used to transport water from an aquifer or water well to a surface for irrigation and drinking purposes; traditional saffron cultivation based on Qanat irrigation in Gonabad has been recognised as one of the globally important agricultural heritage systems (GIAHS) by the FAO [13]) in this region: The first one, called Banghouzhd, has a flow rate of $0.03 \mathrm{~m}^{3} / \mathrm{s}$ (the term $\mathrm{m}^{3} / \mathrm{s}$ refers to cubic metres per second), and the second one, Kamali, has a flow rate of $0.02 \mathrm{~m}^{3} / \mathrm{s}$. Saffron is irrigated four to five times during the vegetative growth stage. For the climatic conditions of Khorasan, mid-October is the best time for the first irrigation of saffron fields [23]. The average application of fertiliser is $182.79 \mathrm{~kg} / \mathrm{ha}$, which is consistent with rates recommended by previous studies (see, e.g., Shahandeh [50]) and the average rate of cattle manure application is 38 tonnes/ha. Cattle manure usage at a 
rate of 30-60 tonnes/ha is among the suggested recommendations for sustainable saffron production [50].

The results show that the youngest and oldest farmers are 24 and 79 years old, respectively, with an average level of education of 7.13 years. The majority of farmers did not attend training sessions, probably because they do not have convenient access to training courses and extension services. From the sampled saffron growers, only $24 \%$ have crop insurance. This is possibly due to inappropriate compensation schemes. The majority of farmers believe that the actual restitution paid for the total damage to saffron growers is less than the actual economic damage. Table 2 shows that the average amount of the farms' harvested saffron flowers varies widely over the years. The lowest output was related to the first year of production, which is in line with our expectations, since saffron's vegetative growth and stigma yields are typically low in the first year. From the second year, increased yields are achieved, which is due to the increasing numbers of daughter corms [12]. Furthermore, it was observed that a significant difference exists among the farmers in their input usage. Putting all these results together, it can be concluded that the technical efficiency of saffron production significantly differs from farm to farm, and from year to year. Our findings reveal that a saffron field, which lasts six years, generates income that is two to three times more than its establishment costs. Based on the six-year average, saffron corm, labour, water, cattle manure, land, and chemical fertilizer account for approximately $32,25,22.5,11.5,5.5$, and 3.5 percent of costs, respectively. However, farm monitoring indicates that there is still room for reducing production costs and making efficiency gains.

\subsection{Technical Efficiency}

An input-oriented DEA model was used to estimate the technical efficiency of the sample farms. Table 3 gives the frequency distribution of efficiency scores in the year of data collection (2019). Additionally, in another visualization, the distribution of VRS values is represented in Figure 2. Table 3 shows that, of the 110 sample farms, $20 \%$ of the farms are technically efficient under VRS, while only $9.1 \%$ of farms are technically efficient under CRS. The mean pure technical efficiency value is 0.83 , ranging from 0.5 to 1 . The average score of 0.77 for the overall efficiency implies that some farmers are not utilising their production resources efficiently, and also indicates that the amount of inputs could be reduced by almost $23 \%$ at the current output level and technology. The scale efficiency is in the range from 0.55 to 1 , with a mean of 0.93 , indicating that some sample farms are not operating at an optimal scale.

Table 3. Frequency distributions of technical and scale efficiencies of the saffron farms.

\begin{tabular}{|c|c|c|c|c|c|c|c|}
\hline & \multirow{2}{*}{$\begin{array}{c}\text { Efficiency } \\
\text { Range }\end{array}$} & \multicolumn{2}{|c|}{$\begin{array}{l}\text { Overall Technical Efficiency } \\
\text { (CRS) }\end{array}$} & \multicolumn{2}{|c|}{$\begin{array}{c}\text { Pure Technical Efficiency } \\
\text { (VRS) }\end{array}$} & \multicolumn{2}{|c|}{ Scale Efficiency } \\
\hline & & Freq. & $\%$ & Freq. & $\%$ & Freq. & $\%$ \\
\hline \multirow{9}{*}{ Frequency } & $0.3-0.40$ & 1 & 0.9 & - & - & - & - \\
\hline & $0.41-0.5$ & 1 & 0.9 & 1 & 0.9 & - & - \\
\hline & $0.51-0.6$ & 8 & 7.3 & 5 & 4.5 & 1 & 0.9 \\
\hline & $0.61-0.70$ & 19 & 17.3 & 8 & 7.3 & 4 & 3.6 \\
\hline & $0.71-0.8$ & 39 & 35.5 & 30 & 27.3 & 8 & 7.3 \\
\hline & $0.81-0.9$ & 23 & 20.9 & 32 & 29.1 & 9 & 8.2 \\
\hline & $0.91-0.99$ & 9 & 8.2 & 12 & 10.9 & 78 & 70.9 \\
\hline & 1 & 10 & 9.1 & 22 & 20 & 10 & 9.1 \\
\hline & Total DMUs & 110 & 100 & 110 & 100 & 110 & 100 \\
\hline \multirow{4}{*}{$\begin{array}{l}\text { Summary } \\
\text { statistics of } \\
\text { efficiency } \\
\text { score }\end{array}$} & Mean & 0.77 & & 0.83 & & 0.93 & \\
\hline & SD & 0.13 & & 0.12 & & 0.09 & \\
\hline & Min. & 0.39 & & 0.50 & & 0.55 & \\
\hline & Max. & 1 & & 1 & & 1 & \\
\hline
\end{tabular}




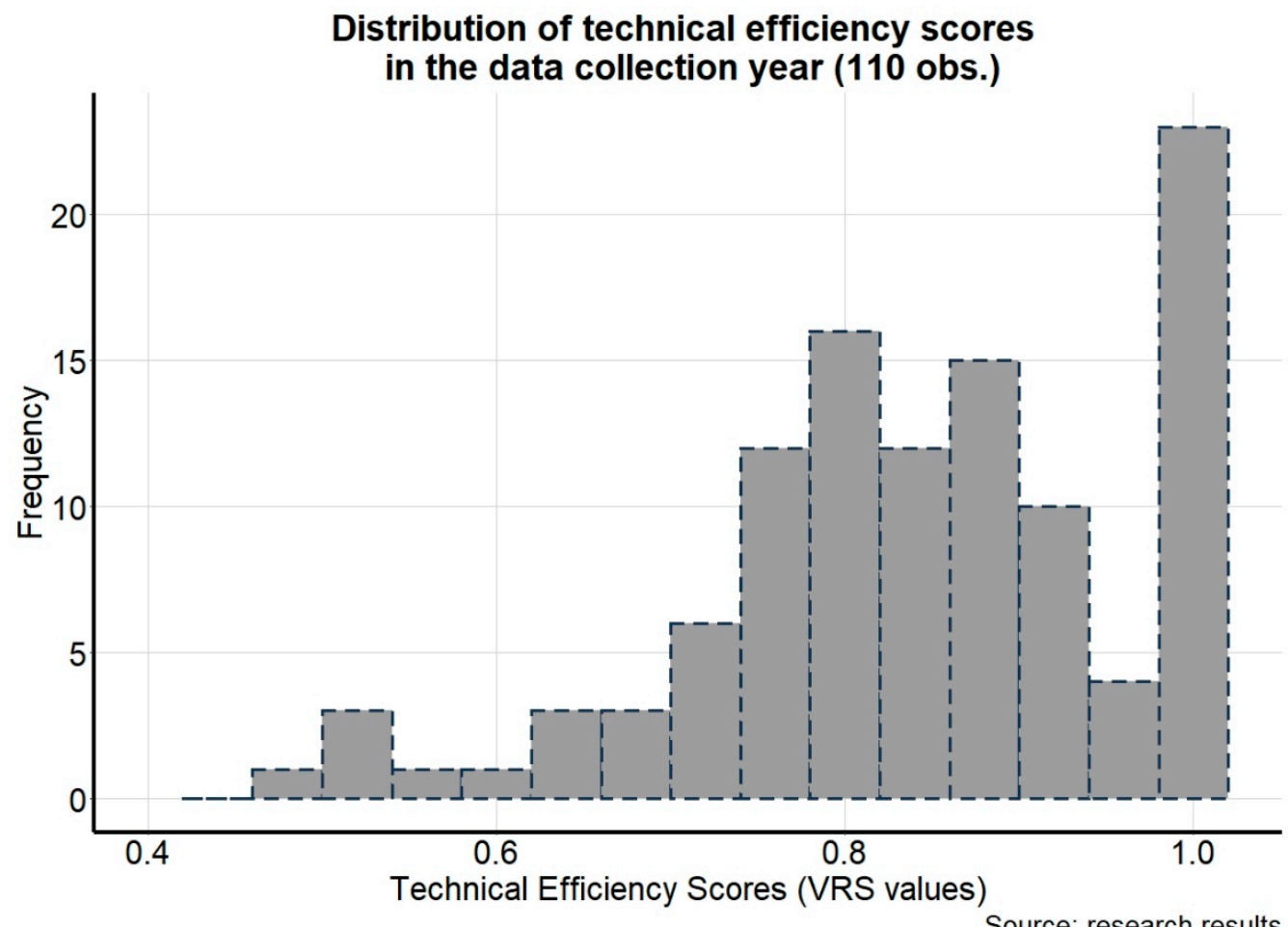

Figure 2. Distribution of technical efficiency scores in the data collection year (110 observations).

The summary statistics of the efficiency scores for each year of the six-year production cycle are also given in Table 4, which show that the efficiency scores change considerably over the years. The lowest and highest technical and scale efficiency scores are obtained in the first and sixth years of harvesting, respectively.

Table 4. Descriptive statistics of efficiency scores in the first six years.

\begin{tabular}{|c|c|c|c|c|c|c|c|}
\hline & & 1st Year & 2nd Year & 3rd Year & 4th Year & 5th Year & 6th Year \\
\hline \multirow{4}{*}{$\begin{array}{l}\text { Overall } \\
\text { technical } \\
\text { efficiency }\end{array}$} & Mean & 0.45 & 0.80 & 0.89 & 0.91 & 0.91 & 0.92 \\
\hline & SD & 0.26 & 0.15 & 0.09 & 0.07 & 0.06 & 0.08 \\
\hline & Min. & 0.05 & 0.25 & 0.43 & 0.64 & 0.70 & 0.70 \\
\hline & Max. & 1 & 1 & 1 & 1 & 1 & 1 \\
\hline \multirow{4}{*}{$\begin{array}{l}\text { Pure } \\
\text { technical } \\
\text { efficiency }\end{array}$} & Mean & 0.59 & 0.87 & 0.91 & 0.92 & 0.93 & 0.93 \\
\hline & SD & 0.24 & 0.13 & 0.09 & 0.07 & 0.07 & 0.08 \\
\hline & Min. & 0.18 & 0.44 & 0.65 & 0.66 & 0.71 & 0.71 \\
\hline & Max. & 1 & 1 & 1 & 1 & 1 & 1 \\
\hline \multirow{4}{*}{$\begin{array}{c}\text { Scale } \\
\text { efficiency }\end{array}$} & Mean & 0.78 & 0.92 & 0.97 & 0.99 & 0.99 & 0.99 \\
\hline & $\mathrm{SD}$ & 0.28 & 0.09 & 0.07 & 0.02 & 0.03 & 0.02 \\
\hline & Min. & 0.08 & 0.53 & 0.43 & 0.86 & 0.89 & 0.91 \\
\hline & Max. & 1 & 1 & 1 & 1 & 1 & 1 \\
\hline
\end{tabular}

As previously noted, the CRS assumption is appropriate in cases where all DMUs operate at an optimal scale. However, some constraints may cause a DMU not to operate at its optimal scale. Therefore, we used the VRS model of DEA for further analysis.

\subsection{Factors Influencing Technical Efficiency}

The estimates of the OLS and BTR with cross-sectional data are provided in Table 5. The $\mathrm{F}$ and Wald tests show that the factors in the models influence the technical efficiency. Seven out of the nine variables included in the models affect the technical efficiency of 
saffron farms significantly. In both models, factors such as education, planting density, and farm size influence the technical efficiency negatively, whereas income, household size, age of the farm, and attending training courses show a positive relationship with efficiency. Meanwhile, others, such as farmer's age and the use of crop insurance, are insignificant.

Table 5. OLS and BTR results of factors influencing technical efficiency (cross-sectional data).

\begin{tabular}{|c|c|c|c|c|}
\hline Variable & \multicolumn{2}{|c|}{ OLS } & \multicolumn{2}{|c|}{ BTR } \\
\hline & \multicolumn{2}{|c|}{ Coefficient } & \multicolumn{2}{|c|}{ Observed Coefficient } \\
\hline Farmer's age (year) & \multicolumn{2}{|c|}{$\begin{array}{l}-0.0002893 \\
(0.0005585)\end{array}$} & \multicolumn{2}{|c|}{$\begin{array}{l}-0.0010755 \\
(0.0007307)\end{array}$} \\
\hline Education (year) & \multicolumn{2}{|c|}{$\begin{array}{c}-0.0039596^{* *} \\
(0.0018143)\end{array}$} & \multicolumn{2}{|c|}{$\begin{array}{c}-0.0046747^{* *} \\
(0.0021135)\end{array}$} \\
\hline Income (IRR million) & \multicolumn{2}{|c|}{$(0.0006839)$} & \multicolumn{2}{|c|}{$\begin{array}{c}0.0026016^{* * *} \\
(0.0006479)\end{array}$} \\
\hline Household size (person) & \multicolumn{2}{|c|}{$\begin{array}{c}0.0106486^{* * * *} \\
(0.0029393)\end{array}$} & $0.0150109^{* * *}$ & \\
\hline $\begin{array}{l}\text { Planting density } \\
\text { (tonnes/ha) }\end{array}$ & \multicolumn{2}{|c|}{$\begin{array}{c}-0.0159393^{* * *} \\
(0.0058302)\end{array}$} & \multicolumn{2}{|c|}{$\begin{array}{c}-0.0209548^{* * *} \\
(0.0068499)\end{array}$} \\
\hline Farm size (ha) & \multicolumn{2}{|c|}{$\begin{array}{c}-0.0314697^{*} \\
(0.0165183)\end{array}$} & \multicolumn{2}{|c|}{$\begin{array}{c}-0.0429285 * \\
(0.0252818)\end{array}$} \\
\hline Age of the farm (year) & \multicolumn{2}{|c|}{$0.0085347^{* * *}$} & \multicolumn{2}{|c|}{$\begin{array}{c}0.0063351^{* * * *} \\
(0.0018986)\end{array}$} \\
\hline Insurance (dummy) & \multicolumn{2}{|c|}{$\begin{array}{c}0.018882 \\
(0.0140989)\end{array}$} & 0.0226544 & $(0.0150991)$ \\
\hline $\begin{array}{l}\text { Training course } \\
\text { (dummy) }\end{array}$ & \multicolumn{2}{|c|}{$0.0319484^{* *}$} & \multicolumn{2}{|c|}{$\begin{array}{l}0.0372746 \text { * } \\
(0.0199329)\end{array}$} \\
\hline Constant & \multicolumn{2}{|c|}{$\begin{array}{c}0.8294427^{* * * *} \\
(0.0467917)\end{array}$} & \multicolumn{2}{|c|}{$(0.0617453)$} \\
\hline Sigma & \multicolumn{2}{|c|}{ 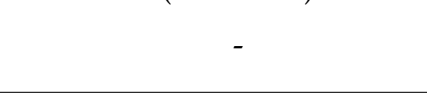 } & \multicolumn{2}{|c|}{$\begin{array}{c}0.0770393 * * * \\
(0.0064382)\end{array}$} \\
\hline \multirow{5}{*}{ Model fit measures } & $\mathrm{F}(9,100)$ & $11.54^{* * *}$ & Wald chi2 (9) & $103.65^{* * *}$ \\
\hline & Root MSE & 0.0788 & Log-likelihood & 236.49 \\
\hline & R-squared & 0.331 & Upper limit & 1 \\
\hline & Adj. R-squared & 0.302 & Truncated obs. & 22 \\
\hline & Total obs. & 110 & Total obs. & 110 \\
\hline
\end{tabular}

Note: ${ }^{*}, * *$, and ${ }^{* * *}$ denote significance levels of $10 \%, 5 \%$, and $1 \%$, respectively. Standard errors are shown in parentheses. We did not round the decimals in this table to give the readers the chance to exactly estimate the t-ratio.

In order to give a general picture of the magnitude of the coefficients, we interpreted the estimated coefficients of different models as the percentage changes in TE due to one unit increase in the levels of the explanatory variables. The coefficient of a dummy variable reveals the percentage change in the TE as the dummy variable changes from 0 to 1 , holding the other factors constant. The estimated coefficient of the education level is negative and significant, implying that educated farmers are less efficient than others. An additional year of education leads to a $0.39 \%$ and $0.46 \%$ decrease in technical efficiency, based on the OLS and truncated models, respectively. Farm monitoring shows that educated farmers are more willing to overuse chemical fertilisers, which may decrease the yields and, as a consequence, result in efficiency loss. This result is confirmed by the extension agents in the study area, and is in line with the findings of Dourandish et al. [51], who stated that, in spite of their negative effects on the yields of saffron farms in Gonabad, chemical fertilisers have been widely overused by educated saffron growers. The positive and significant coefficient of income indicates that farmers with higher incomes are more efficient. IRR 1 million in additional income leads to a $0.21 \%$ and $0.26 \%$ increase in the TE according to the OLS and BTR models, respectively. This finding is in line with our expectation, as acquiring production inputs is less of a constraint for higher income farmers. For instance, approximately eighty labourers are needed to hand weed one hectare of saffron [52]. 
Nevertheless, many farmers cannot afford it and, therefore, they were not able to apply an efficient weed control, which can reduce yields. Manure is another constraining input, with saffron generally benefiting from the application of manure [50]. However, there are limitations when it comes to applying manure in the saffron-producing areas of Gonabad due to the cost of manure and its affordability.

The estimated coefficient of household size is positive and statistically significant at the $1 \%$ level. One additional member of the household leads to a $1.1 \%$ and $1.5 \%$ increase in the TE, based on the OLS and BTR models, respectively. Saffron is one of the most labour-intensive crops. Large families can use family labour to meet their requirements, making the need for labour less constraining. Our findings comply with the findings of Oyetunde-usman and Olagunju [53]. However, additional findings, such as in Mukhtar et al. [26] and Tan et al. [54], revealed an inverse relationship between household size and efficiency. As expected, the coefficient of planting density is negative, showing that an increase in planting density would result in a reduction in TE. One more tonne of corm plantation per hectare leads to a $1.6 \%$ and $2.1 \%$ decrease in the TE, according to the OLS and BTR models, respectively. This result is in line with the findings of Umanath and David Rajasekar [55], but in contrast with Wongnaa and Awunyo-Vitor [56], who found seeding density to be positively and significantly related to the output of maize in two agroecological zones of Ghana. Nevertheless, none of these studies dealt with perennial crops. Farm size is negatively significant at the $10 \%$ level, implying that small farms were more technically efficient than the larger ones. One more hectare increase in the farm size can decrease the TE by $3.2 \%$ and $4.3 \%$ on average, according to the OLS and BTR models, respectively. Saffron cultivation is time consuming, labour intensive, and has a short harvesting season of about 20-30 days. Our findings suggest that large farms cannot meet the high labour demands with the available labour supply, making them less efficient. This is confirmed by the work of Ugbabe et al. [57], Boubacar et al. [41], and Zulfiqar et al. [25], who have all shown a negative relationship between farm size and efficiency. Another outcome of the OLS and truncated models is the positive and significant effect of the age of the farm on technical efficiency, implying that old farms are more efficient than the others. If the farm becomes older by one year, the TE increases by $0.85 \%$ and $0.63 \%$, according to the OLS and BTR models, respectively. It has already been mentioned that the flowering life of saffron fields in the study region varies from 10 to 15 years, while, with higher densities, this may be reduced to 6 years. Therefore, it is once again confirmed that dense planting reduces technical efficiency by decreasing the flowering life of the saffron farms. The coefficient for the training course is positively significant, suggesting that farmers who attended training sessions were more efficient. Findings indicate that, after attending training sessions, the technical efficiency of saffron production increases by $3.2 \%$ and $3.7 \%$, based on the OLS and truncated models, respectively. This was found to be in line with a study by Mengui et al. [28]. Although the measuring units of the explanatory variables are totally different in the cross-sectional data model, the impact of farm size changes and attending the training sessions was the highest on the TE.

Another aim of the present paper was to investigate the relationship between planting density and the technical efficiency of saffron farms over a six-year production cycle. To this end, the technical efficiency of farms was plotted against the planting density for each year of the cycle (Figure 3). As shown in Figure 3, although dense planting may increase the technical efficiency of farms in the early years, this effect becomes negative in the fifth and sixth years. This means that saffron farms with dense planting were more efficient in the early years, but that the efficiency of such farms declined in the following years. Thus, dense planting systems do not always have greater efficiency. Our field observations suggest that almost all saffron growers are well aware that high-density saffron cultivation reduces the flowering life of their farms, but some have preferred higher corm planting densities in order to make more profit and offset yield losses from the early years. 


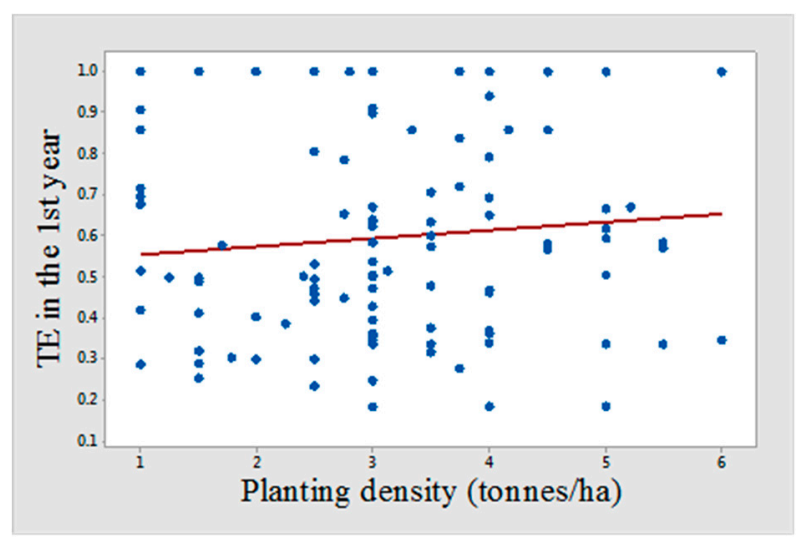

(a)

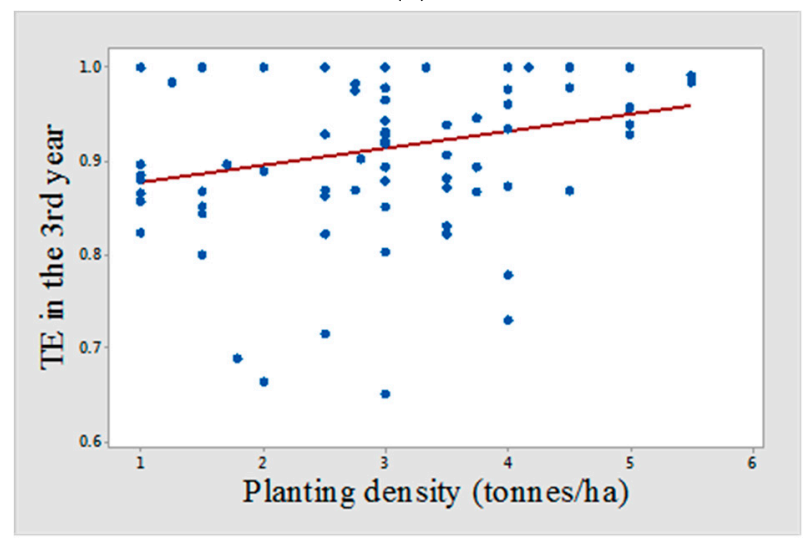

(c)

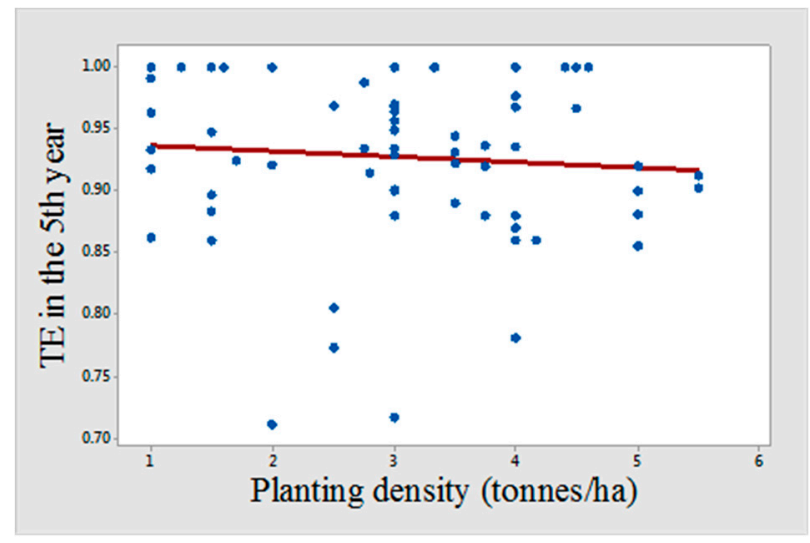

(e)

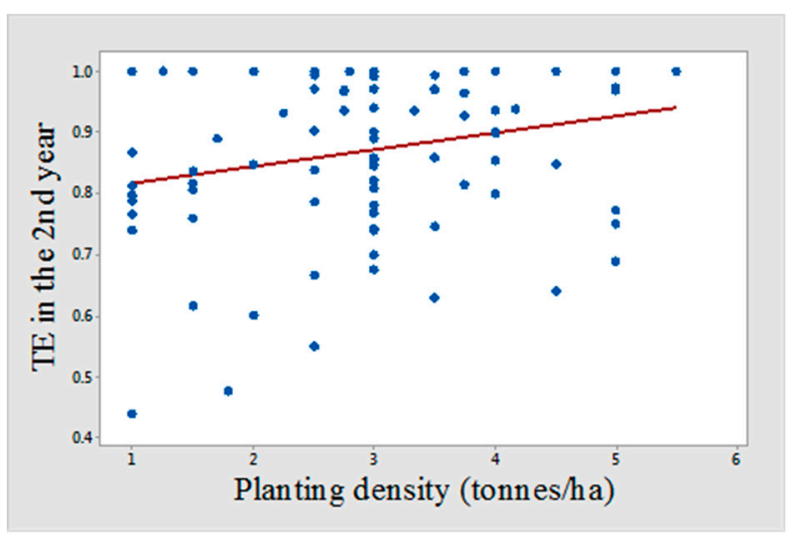

(b)

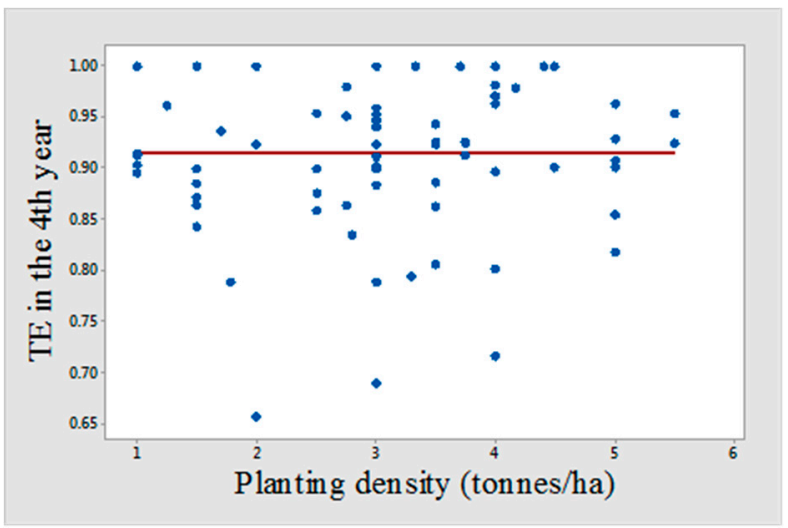

(d)

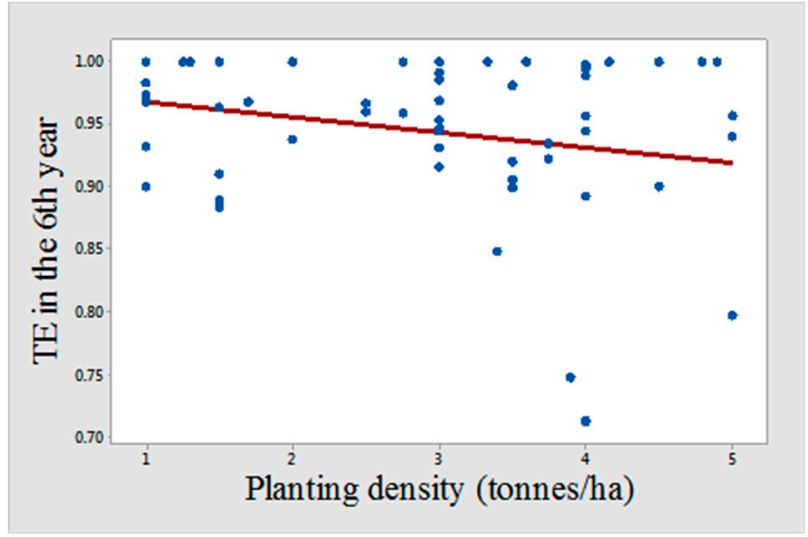

(f)

Figure 3. Panels (a-f) depict the relationship between corm planting density and technical efficiency in the first six years of farm utilisation.

As the final part of this analysis, we implemented an unbalanced panel data model to investigate the effect of planting density on the technical efficiency over a six-year production cycle. The OLS and BTR were fitted based on unbalanced panel data of 110 farms over a six-year period. Firstly, the variable of interest was tested for stationarity. Table 6 presents the Fisher unit root test for the variable of TE; the test statistics confirmed that the variable is stationary. It should be pointed out that the normality of the error term assumption was checked and determined to be tenable. 
Table 6. Results of the unit root test.

\begin{tabular}{ccc}
\hline \multirow{2}{*}{ Variables } & \multicolumn{2}{c}{ Fisher Test } \\
\cline { 2 - 3 } & Statistic & $p$-Value \\
\hline Technical Efficiency & 153.1089 & 0.00 \\
\hline
\end{tabular}

After the stationary analysis, the panel models were estimated by considering both random and fixed effects (Tables 7 and 8). Given the importance of the age of the farms to the flowering ability, the time-specific effect was also taken into account when estimating the fixed-effect model. The model selection criteria, including LR and AIC, show that the two-way fixed-effect model is the most efficient estimator. Based on these results, high-density planting systems, even over a six-year period, would reduce the technical efficiency of farms. This means that dense planting would render farmers unable to meet the minimum levels of inputs for producing a given quantity of output, resulting in higher production costs per unit of output for a farm, and hence the inability of the saffron growers to maximise profit. Therefore, we can conclude that the practice of high-density saffron cultivation systems in a six-year production cycle has a negative effect on the efficiency of the farms.

Table 7. Panel OLS estimation results of the effect of corm planting density on technical efficiency.

\begin{tabular}{ccccc}
\hline Variable & Random Effect & Fixed Effect & Fixed Effect & Fixed Effect \\
\hline Ln(Corm) & 0.0092 & $-0.5549^{* * *}$ & $0.0228^{*}$ & $-0.2715^{* *}$ \\
& $(0.0179)$ & $(0.2033)$ & $(0.0130)$ & $(0.1287)$ \\
Constant & $0.8306^{* * *}$ & $1.3383^{* * *}$ & $0.57192^{* * *}$ & $0.8305^{* * *}$ \\
& $(0.0201)$ & $(0.2207)$ & $(0.0192)$ & $(0.1407)$ \\
\hline Farmer-specific effect & & $\sqrt{ }$ & $\sqrt{ }$ \\
Time-specific effect & & & $\sqrt{ }$ & $\sqrt{ }$ \\
\hline LR & 0.27 & $287.06^{* * *}$ & $313.74^{* * *}$ & $739.39^{* * *}$ \\
\hline AIC & -204.9845 & -273.778 & -508.465 & -716.113 \\
\hline Total observations & \multicolumn{2}{c}{483}
\end{tabular}

Note: ${ }^{*}, * *$ and ${ }^{* * *}$ denote significance levels of $10 \%, 5 \%$, and $1 \%$, respectively. Standard errors are shown in parentheses.

Table 8. Panel BTR estimation results of the effect of corm planting density on technical efficiency.

\begin{tabular}{ccccc}
\hline Variable & Random Effect & Fixed Effect & Fixed Effect & Fixed Effect \\
\hline Ln(Corm) & 0.0079 & $-0.2123^{* *}$ & $0.0202^{*}$ & $-0.2937^{* * *}$ \\
& $(0.0216)$ & $(0.1066)$ & $(0.0116)$ & $(0.0929)$ \\
Constant & $0.8213^{* * *}$ & $1.0184^{* * *}$ & $0.5879^{* * *}$ & $0.7928^{* * *}$ \\
& $(0.0149)$ & $(0.1133)$ & $(0.1424)$ & $(0.0161)$ \\
\hline farmer specific effect & & $\sqrt{ }$ & $\sqrt{ }$ \\
time specific effect & & & $\sqrt{ }$ & $\sqrt{ }$ \\
\hline LR & 0.22 & $446.78^{* * *}$ & $312.26^{* * *}$ & $1073.09^{* * *}$ \\
\hline AIC & 68.0338 & -39.6037 & -97.5983 & -618.7344 \\
\hline
\end{tabular}

Total observations 483

Note: ${ }^{*}, * *$, and ${ }^{* * *}$ denote significance levels of $10 \%, 5 \%$, and $1 \%$, respectively. Standard errors are shown in parentheses.

Putting all these results together, it is clear that high-density planting systems would not be able to provide economic sustainability for the farms, since a major aspect of sustainability is a long-term timespan. In addition, as we formerly discussed in the introduction of this paper, a saffron plot cannot keep its flowering ability after a certain period of saffron cultivation. Therefore, ecological instability can be an additional negative effect of high-density saffron cultivation. 


\section{Discussion}

In this study, we found that there are significant differences in technical efficiencies among saffron farms and that many saffron farmers were found to be technically inefficient. Therefore, there is a remarkable capacity for increasing efficiency and reducing input costs while maintaining the same production levels. Additionally, in the second stage of the analysis, we were able to determine some of the factors affecting the technical efficiency of the saffron farms. Our findings reveal that several factors, including level of education, attending training courses, income, household size, age of the farm, planting density, and farm size, are the main determinants. Furthermore, our findings suggest that planting density had a significantly negative impact on technical efficiency, while the impact of the age of the farm was found to be positive. Additionally, contrary to the belief of some farmers, our findings suggest that dense planting systems result in efficiency losses and higher production costs per unit of output over a six-year cycle. This negative effect of planting density on the efficiency of saffron farms should be dealt with by warning the saffron growers of the hindering effects of high corm planting densities on the profitability of their farms. Field observations in Gonabad county show that the low market value of land is one of the main reasons for implementing dense planting systems in the region. Some farmers plant saffron in higher densities and harvest higher yields in earlier years, but then leave that land after a few years to grow saffron on other virgin lands. Growing saffron on land that has already been cultivated with saffron is not possible for many years. Dense planting systems are therefore threatening to both saffron production and short-term land use sustainability. The abandoning of agricultural lands after six years of dense plantation of saffron corm and employing new virgin lands again under the dense planting system are definitely against any sustainable farming practices and sustainable agriculture principles, which are defined and supported by many researchers and international organisations as soil quality and land conservation. These values are neglected in saffron production $[17,18]$. Meanwhile, the study region is also currently facing land availability issues and irrigation water restrictions. Thus, the development of an efficient market under which land is traded at a fair price is one solution. Implementing local policies that restrict using virgin land for saffron production could be another solution. We found that farmers who attended training courses were more efficient; however, few farmers have attended these courses. Thus, it is necessary to increase the farmers' access to extension services and motivate them to attend extension programs and courses by adopting strategies, such as organising seasonal training programs/workshops, creating extension communities, travelling to the farmers, and the creation of digital possibilities for the purpose of teaching the most efficient production methods. Some saffron growers, especially educated ones, had a tendency to overuse chemical fertilisers, probably because of the lack of knowledge on the consequences of overusing them. The overuse of chemical fertilisers in saffron production not only reduces the yields and efficiency of production, but could also result in serious health issues for consumers. Furthermore, the over application of fertilisers can result in environmental damage and soil-water resource contamination. There is, thus, a need to convey the message to saffron growers that chemical fertilisers should be used at an optimum level. Moreover, the majority of farmers in the saffron-producing areas of Gonabad faced negative cash flow during the growing and harvesting periods. There were liquidity limitations on the use of some inputs, including labour and manure, rendering farmers unable to acquire and apply inputs as needed. These liquidity constraints could be reduced by alleviating credit constraints and, thus, enhancing the acquisition of inputs. Hence, the government should link farmers directly to financial institutions, such as banks and microfinance institutions.

\section{Conclusions}

This study aimed to investigate the technical efficiency of saffron production in order to determine the factors affecting the efficiencies of saffron farms and to identify the challenges faced by saffron growers in Gonabad county in the north-eastern part of Iran. We therefore applied a two-step approach for this analysis. Our study findings suggest that there is 
considerable room for efficiency gains. Additionally, the age of the farm, planting density, income, household size, level of education, training courses, and farm size were found to significantly affect the technical efficiency. The majority of saffron growers in this region face a lot of challenges, including high input costs, a lack of extension services, a lack of proper production knowledge, and a tendency towards the overuse of chemical inputs. Policywise, this study provides some guidelines for policymakers and practitioners. Some saffron growers were found to be over exploiting arable lands through the use of dense planting systems and/or they were found to not be using optimal levels of inputs because of either liquidity limitations or a lack of knowledge. The inappropriate use of production inputs in saffron cultivation may not only result in technical inefficiencies, but also threaten the ecological sustainability of saffron production in the saffron-producing areas of Gonabad. One immediate step that government agencies could take would be the provision of the necessary education, training, and extension services focused on the threats of dense saffron planting and chemical fertiliser overuse in order to encourage efficient and sustainable saffron production in the study region. The international expansion of saffron production due to its high value can be accomplished by repeating the same practice of implementing a dense planting system, which is totally against the principles of sustainable agriculture. The already unsustainable practice of dense plantation, exploiting land abundancy, and as a result land abandonment can be avoided in any other countries where saffron production might potentially be an attractive choice for farmers by considering the experience of Iran. Future research on abandoned saffron farms could also be helpful, as this would help us to understand why saffron farms are abandoned in the first place in order to provide more knowledge on appropriate policies for improved farm and resources management and less saffron farmland abandonment.

Author Contributions: Conceptualization, M.R., A.D. and T.J.J.; methodology, M.R., T.J.J. and M.A.; software, M.R. and M.A.; validation, A.D. and T.J.J.; formal analysis, M.R., T.J.J. and M.A.; investigation, M.R.; resources, M.R.; data curation, M.R. and T.J.J.; writing-original draft preparation, M.R.; writing-review and editing, M.R. and T.J.J.; visualization, M.R. and T.J.J.; supervision, A.D.; project administration, A.D.; funding acquisition for proofreading and open access publication, T.J.J. All authors have read and agreed to the published version of the manuscript.

Funding: This research did not receive any specific grant from funding agencies in the public, commercial, or not-for-profit sectors. This research was conducted during the presence of the four authors at the Ferdowsi University of Mashhad (FUM) and University of Tehran (UT) in Iran and the Leibniz Institute of Agricultural Development in Transition Economies (IAMO) in Germany.

Institutional Review Board Statement: Not applicable.

Informed Consent Statement: Not applicable.

Data Availability Statement: Not applicable.

Acknowledgments: The open access publication of this article was funded by the Open Access Fund of the Leibniz Association and open access fund of Leibniz Institute of Agricultural Development in Transition Economies (IAMO). The authors are grateful to Mary Wales for her proofreading support. The authors also like to thank two anonymous reviewers for very helpful comments on an earlier draft of this paper.

Conflicts of Interest: The authors declare no conflict of interest.

\section{References}

1. Sahabi, H.; Feizi, H.; Karbasi, A. Is saffron more energy and economic efficient than wheat in crop rotation systems in northeast Iran? Sustain. Prod. Consum. 2016, 5, 29-35. [CrossRef]

2. Jafari-Ghanavati, M.; Saket, S. Chapter 1-Saffron and Folklore. In Saffron: Science, Technology and Health; Koocheki, A., KhajehHosseini, M.B.T.-S., Eds.; Woodhead Publishing: Sawston, UK, 2020; pp. 3-13. ISBN 978-0-12-818638-1.

3. Rezvani-Moghaddam, P. Chapter 8-Ecophysiology of Saffron. In Saffron: Science, Technology and Health; Inoocheki, A., KhajehHosseini, M.B.T.-S., Eds.; Woodhead Publishing: Sawston, UK, 2020; pp. 119-137. ISBN 978-0-12-818638-1. 
4. Shahnoushi, N.; Abolhassani, L.; Kavakebi, V.; Reed, M.; Saghaian, S. Chapter 21-Economic Analysis of Saffron Production. In Saffron: Science, Technology and Health; Koocheki, A., Khajeh-Hosseini, M.B.T.-S., Eds.; Woodhead Publishing: Sawston, UK, 2020; pp. 337-356. ISBN 978-0-12-818638-1.

5. Rashed-Mohassel, M.-H. Chapter 4-Evolution and Botany of Saffron (Crocus sativus L.) and Allied Species. In Saffron: Science, Technology and Health; Koocheki, A., Khajeh-Hosseini, M.B.T.-S., Eds.; Woodhead Publishing: Sawston, UK, 2020; pp. 37-57. ISBN 978-0-12-818638-1.

6. World Bank Saffron: A Major Source of Income and an Alternative to Poppy. Available online: https://www.worldbank.org/en/ news / feature/2015/01/20/saffron-major-source-income-alternative-poppy (accessed on 30 November 2021).

7. UNODC Executive Summary Policy Implications. Available online: https://www.unodc.org/unodc/en/data-and-analysis/ wdr-2021_booklet-1.html (accessed on 30 November 2021).

8. ITC Trade Map-Value of saffron exported by Iran in 2018 [online database]. Available online: https://www.trademap.org/Index. aspx (accessed on 16 May 2020).

9. Bazrafshan, O.; Ramezani Etedali, H.; Gerkani Nezhad Moshizi, Z.; Shamili, M. Virtual water trade and water footprint accounting of Saffron production in Iran. Agric. Water Manag. 2019, 213, 368-374. [CrossRef]

10. Mohammadi, H.; Kashefi, M.; Abolhasani, L. Effect of Marketing Strategies on Export Performance of Agricultural Products: The Case of Saffron in Iran. J. Agric. Sci. Technol. 2019, 21, 785-798.

11. Ministry of agriculture Jihad. Available online: https://www.maj.ir (accessed on 17 May 2020).

12. Koocheki, A.; Seyyedi, S.-M. Chapter 7-Saffron "Seed", the Corm. In Saffron: Science, Technology and Health; Koocheki, A., Khajeh-Hosseini, M.B.T.-S., Eds.; Woodhead Publishing: Sawston, UK, 2020; pp. 93-118. ISBN 978-0-12-818638-1.

13. Khajeh-Hosseini, M.; Fallahpour, F. Chapter 12-Emerging Innovation in Saffron Production. In Saffron: Science, Technology and Health; Koocheki, A., Khajeh-Hosseini, M.B.T.-S., Eds.; Woodhead Publishing: Sawston, UK, 2020; pp. 205-216. ISBN 978-0-12-818638-1.

14. FAO. The Future of Food and Agriculture. Cause for Hope and Concern-Trends and Challenges; FAO: Rome, Italy, $2017 ;$ p. 163.

15. Zulfiqar, F.; Thapa, G.B. Determinants and intensity of adoption of "better cotton" as an innovative cleaner production alternative. J. Clean. Prod. 2018, 172, 3468-3478. [CrossRef]

16. Asimeh, M.; Nooripoor, M.; Azadi, H.; Van Eetvelde, V.; Sklenička, P.; Witlox, F. Agricultural land use sustainability in Southwest Iran: Improving land leveling using consolidation plans. Land Use Policy 2020, 94, 104555. [CrossRef]

17. Reytar, K.; Hanson, C.; Henninger, N. Indicators of Sustainable Agriculture: A Scoping Study. Creat. Sustain. Food Futur. 2014, 1-20. Available online: https:/ / www.wri.org/research/indicators-sustainable-agriculture-scoping-analysis (accessed on 30 November 2021).

18. Trigo, A.; Marta-Costa, A.; Fragoso, R. Principles of sustainable agriculture: Defining standardized reference points. Sustainability 2021, 13, 4086. [CrossRef]

19. Ait-Oubahou, A.; El-Otmani, M. Saffron cultivation in Morocco. In Saffron: Crocus sativus L.; Negbi, M., Ed.; Gordon and Breach: Amsterdam, The Netherlands, 1999.

20. Ranjbar, A.; Emami, H.; Khorassani, R.; Karimi Karouyeh, A.R. Soil quality assessments in some Iranian saffron fields. J. Agric. Sci. Technol. 2016, 18, 865-878.

21. Yau, S.K.; Nimah, M. Spacing effects on corm and flower production of saffron (Crocus sativus). Leban. Sci. J. 2004, 5, 1-8.

22. Saeidirad, M.-H. Chapter 11-Mechanization of Saffron Production. In Saffron: Science, Technology and Health; Koocheki, A., Khajeh-Hosseini, M.B.T.-S., Eds.; Woodhead Publishing: Sawston, UK, 2020; ISBN 978-0-12-818638-1.

23. Koocheki, A.; Fallahi, H.-R.; Jami-Al-Ahmadi, M. Chapter 6-Saffron water requirements. In Saffron: Science, Technology and Health; Koocheki, A., Khajeh-Hosseini, M.B.T.-S., Eds.; Woodhead Publishing: Sawston, UK, 2020; pp. 67-92. ISBN 978-0-12-818638-1.

24. Tammaro, F. Saffron. In Saffron: Crocus sativus L.; Negbi, M., Ed.; Gordon and Breach: Amsterdam, The Netherlands, $1999 ;$ p. 148. ISBN 0203303660.

25. Zulfiqar, F.; Datta, A.; Thapa, G.B. Determinants and resource use efficiency of "better cotton": An innovative cleaner production alternative. J. Clean. Prod. 2017, 166, 1372-1380. [CrossRef]

26. Mukhtar, U.; Mohamed, Z.; Shamsudin, M.N.; Sharifuddin, J.; Iliyasu, A. Application of data envelopment analysis for technical efficiency of smallholder pearl millet farmers in Kano state, Nigeria. Bulg. J. Agric. Sci. 2018, 24, $213-222$.

27. Habiyaremye, N.; Tabe-Ojong, M.P.J.; Ochieng, J.; Chagomoka, T. New insights on efficiency and productivity analysis: Evidence from vegetable-poultry integration in rural Tanzania. Sci. Afr. 2019, 6, e00190. [CrossRef]

28. Mengui, K.C.; Oh, S.; Lee, S.H. The Technical Efficiency of Smallholder Irish Potato Producers in Santa Subdivision, Cameroon. Agriculture 2019, 9, 259. [CrossRef]

29. Attipoe, S.G.; Jianmin, C.; Opoku-Kwanowaa, Y.; Ohene-Sefa, F. The Determinants of Technical Efficiency of Cocoa Production in Ghana: An Analysis of the Role of Rural and Community Banks. Sustain. Prod. Consum. 2020, 23, 11-20. [CrossRef]

30. Kazemi, S.H. A Proposal for Designation as a GIAHS Qanat-Basedsaffron Farming System in Gonabad County, Khorasan Razavi Province, Islamic Republic of Iran. 2018. Available online: https:/ /www.fao.org/giahs/giahsaroundtheworld/designated-sites / asia-and-the-pacific/qanat-based-saffron-farming-system-in-gonabad/annexes/en/ (accessed on 30 November 2021).

31. Wickham, H. ggplot2: Create elegant data visualisations using the grammar of graphics. Wiley Interdiscip. Rev. Comput. Stat. 2011, 3, 180-185. [CrossRef] 
32. Sauro, J.; Lewis, J.R. Chapter 6-What Sample Sizes Do We Need? Part 1: Summative Studies. In Quantifying the User Experience: Practical Statistics for User Research; Sauro, J., Lewis, J.R.B.T.-Q.U.E., Eds.; Morgan Kaufmann: Cambridge, MA, USA, 2016; pp. 103-141. ISBN 978-0-12-384968-7.

33. Farrell, M.J. The Measurement of Productive Efficiency. J. R. Stat. Soc. Ser. A 1957, 120, 253-281. [CrossRef]

34. Charnes, A.; Cooper, W.W.; Rhodes, E. Measuring the efficiency of decision making units. Eur. J. Oper. Res. 1978, 2, 429-444. [CrossRef]

35. Wang, X. Irrigation Water Use Efficiency of Farmers and Its Determinants: Evidence from a Survey in Northwestern China. Agric. Sci. China 2010, 9, 1326-1337. [CrossRef]

36. Stolp, C. Strengths and weaknesses of data envelopment analysis: An urban and regional perspective. Comput. Environ. Urban Syst. 1990, 14, 103-116. [CrossRef]

37. De Koeijer, T.J.; Wossink, G.A.A.; Struik, P.C.; Renkema, J.A. Measuring agricultural sustainability in terms of efficiency: The case of Dutch sugar beet growers. J. Environ. Manage. 2002, 66, 9-17. [CrossRef]

38. Toma, E.; Dobre, C.; Dona, I.; Cofas, E. DEA Applicability in Assessment of Agriculture Efficiency on Areas with Similar Geographically Patterns. Agric. Agric. Sci. Procedia 2015, 6, 704-711. [CrossRef]

39. Coelli, T.J.; Prasada Rao, D.S.; O'Donnell, C.J.; Battese, G.E. An Introduction to Efficiency and Productivity Analysis; Springer: New York, NY, USA, 2005; ISBN 0387242651.

40. Pastor, J.T.; Ruiz, J.L.; Sirvent, I. A Statistical Test for Nested Radial Dea Models. Oper. Res. 2002, 50, 728-735. [CrossRef]

41. Boubacar, O.; Hui-qiu, Z.; Rana, M.A.; Ghazanfar, S. Analysis on Technical Efficiency of Rice Farms and Its Influencing Factors in South-western of Niger. J. Northeast Agric. Univ. Engl. Ed. 2016, 23, 67-77. [CrossRef]

42. Tipi, T.; Yildiz, N.; Nargeleçekenler, M.; Çetin, B. Measuring the technical efficiency and determinants of efficiency of rice (Oryza sativa) farms in Marmara region, Turkey. N. Zeal. J. Crop Hortic. Sci. 2009, 37, 121-129. [CrossRef]

43. Toma, L.; March, M.; Stott, A.W.; Roberts, D.J. Environmental efficiency of alternative dairy systems: A productive efficiency approach. J. Dairy Sci. 2013, 96, 7014-7031. [CrossRef]

44. Hansson, H. Are larger farms more efficient?A farm level study of the relationships between efficiency and size on specialized dairy farms in Sweden. Agric. Food Sci. 2008, 17, 325-337. [CrossRef]

45. McDonald, J. Using least squares and tobit in second stage DEA efficiency analyses. Eur. J. Oper. Res. 2009, 197, 792-798. [CrossRef]

46. Banker, R.D.; Natarajan, R. Evaluating Contextual Variables Affecting Productivity Using Data Envelopment Analysis. Oper. Res. 2008, 56, 48-58. [CrossRef]

47. Simar, L.; Wilson, P.W. Estimation and inference in two-stage, semi-parametric models of production processes. J. Econom. 2007, 136, 31-64. [CrossRef]

48. López-Penabad, M.-C.; Maside-Sanfiz, J.M.; Torrelles Manent, J.; Iglesias-Casal, A. Application of the DEA Double Bootstrap to Analyze Efficiency in Galician Sheltered Workshops. Sustainability 2020, 12, 6625. [CrossRef]

49. Hall, P. On the Number of Bootstrap Simulations Required to Construct a Confidence Interval. Ann. Stat. 1986, 14, 1453-1462. [CrossRef]

50. Shahandeh, H. Chapter 5-Soil Conditions for Sustainable Saffron Production. In Saffron: Science, Technology and Health; Koocheki, A., Khajeh-Hosseini, M.B.T.-S., Eds.; Woodhead Publishing: Sawston, UK, 2020; pp. 59-66. ISBN 978-0-12-818638-1.

51. Dourandish, A.; Ramezani, M.; Aminizadeh, M. Investigation of the Effective Factors on Use of Chemical Fertilizers in Saffron Farms (Case study: Gonabad County). Saffron Agron. Technol. 2019, 7, 359-376, (originally in persian). [CrossRef]

52. Bazoobandi, M.; Rahimi, H.; Karimi-Shahri, M.-R. Chapter 10-Saffron Crop Protection. In Saffron: Science, Technology and Health; Koocheki, A., Khajeh-Hosseini, M.B.T.-S., Eds.; Woodhead Publishing: Sawston, UK, 2020; pp. 169-185. ISBN 978-0-12-818638-1.

53. Oyetunde-usman, Z.; Olagunju, K.O. Determinants of Food Security and Technical Efficiency among Agricultural Households in Nigeria. Economies 2019, 7, 103. [CrossRef]

54. Tan, S.; Heerink, N.; Kuyvenhoven, A.; Qu, F. NJAS-Wageningen Journal of Life Sciences Impact of land fragmentation on rice producers' technical efficiency in South-East China. NJAS Wagening. J. Life Sci. 2010, 57, 117-123. [CrossRef]

55. Umanath, M.; David Rajasekar, D. Estimation of Technical, Scale and Economic Efficiency of Paddy Farms: A Data Envelopment Analysis Approach. J. Agric. Sci. 2013, 5, 243-251. [CrossRef]

56. Wongnaa, C.A.; Awunyo-Vitor, D. Scale efficiency of maize farmers in four agro ecological zones of Ghana: A parametric approach. J. Saudi Soc. Agric. Sci. 2019, 18, 275-287. [CrossRef]

57. Ugbabe, O.; Abdoulaye, T.; Kamara, A.; Mbavai, J.; Oyinbo, O. Profitability and Technical Efficiency of Soybean Production in Northern Nigeria. Tropicultura 2017, 35, 203-214. 